\title{
PRESENÇA DA “LUTA” COM CHICA PELEGA: NARRATIVAS CABOCLAS NAS EXPERIÊNCIAS COTIDIANAS
}

Adiles Savoldi

Josiane Geroldi

"Chica Pelega eram todos. E não se matam todos, que são impessoais. Por isso ela não morreu. Ei-la, algures, a trágica Chica Pelega, a filha da terra, irmã

do rio, basta olhar e querer vê-la."

(Vasconcellos, 2008)

“Quem viu Chica Pelega, viu fogo no céu e viu sangue no chão”.

Vicente Telles

\begin{abstract}
Resumo
O texto discorre acerca das narrativas populares entre população cabocla do oeste catarinense. Seleciona o personagem conhecido como Chica Pelega, que teria acompanhado os fatos do Contestado, deslocando-se de Limeira (atual Joaçaba) em direção ao norte, ao local dos combates. Recupera, criticamente, o contexto em que teria surgido o personagem. Analisa a revivescência e os usos feitos pela população local acerca de Chica Pelega.
\end{abstract}

Palavras chave: Contestado; narrativas; Chica Pelega.

\footnotetext{
${ }^{1}$ Esta pesquisa faz parte do projeto "Nas margens do Rio Uruguai: saberes locais das populações ribeirinhas", com financiamento -FAPE da UNOCHAPERCÓ - Grupo de Pesquisa "Mudanças culturais e identidades.”. Apresentado no Seminário Internacional Fazendo Gênero de 2010.
} 
Nas narrativas orais das populações caboclas do Oeste de Santa Catarina são recorrentes as alusões às personagens como Chica Pelega, "São João Maria" e outras figuras lendárias, sejam de cunho religioso ou político. A população cabocla do Oeste Catarinense tem construído sua história ancorada nas leituras das experiências de vida dos ancestrais e seus relatos sobre as revoluções riograndenses, e posteriormente a do Contestado.

Nos últimos anos, o Contestado (1912-1916) tem sido revisitado por diferentes abordagens teóricas, políticas, culturais, religiosas, etc. (AURAS (1994), SERPA (1999), THOME (1983), VASCONCELOS (2008)), além de diversas dissertações e teses acadêmicas. As abordagens configuram diferentes interpretações, no entanto, também apresentam convergências como, por exemplo: a descentralização política, com a República, que outorgou maior autonomia aos Estados; a disputa da divisa entre Santa Catarina e Paraná, o que implicaria a reconfiguração geográfica dos mapas; as ações do Sindicato Farqhuar e a expulsão da população ao longo da ferrovia SP-RS, conforme a concessão de terras (ocupadas) em troca da construção da estrada; o milenarismo; disputas políticas entre frações fazendeiras locais; a separação do Estado da Igreja com a constituição republicana e as relações assimétricas entre monges e clero oficial católico; a disputa entre coronéis/caboclos (com clivagens internas); adesão ou retirada das "gentes do coronel" ao movimento e a subalternidade da "população cabocla".

Segundo Vinhas de Queiroz (1966), a construção da Estrada de Ferro de São Paulo ao Rio Grande do Sul pela empresa americana Brazil Railway Company que recebeu do governo 15 km de cada lado da Ferrovia, ocasionou a revolta da população que habitava determinadas áreas.

A população cabocla foi protagonista da luta pela terra, orientada pelo Monge José Maria. A crença nos monges no Sul do país se constitui como um patrimônio cultural. Destacamos alguns dados biográficos sobre os monges. Embora as diferentes práticas e tempos vividos pelos monges, revelem uma cronologia diferenciada, no imaginário popular há uma integração dos três, ou melhor, é construída a idéia de uma sucessão. Outras afirmações revelam que só existiu um monge e que este ainda está presente.

Segundo Serpa (1999), João Maria de Agostinho nasceu na Itália. Era descrito com cabelos longos e grisalhos, barba longa e olhar meigo. "Era considerado indigente e se fez presente em diferentes localidades como Pará, local de sua chegada, Rio de 
Janeiro, Sorocaba (SP), Campestre de Santa Maria (RS), Lages,

Mafra e Lapa, mas é a partir de Sorocaba que começa sua atividade missionária”. (SERPA, 1999, p. 32).

Uma das características marcantes de João Maria foi a prática de erguer cruzes em diferentes lugares, em especial, onde pernoitava em suas andanças. Há registros de um cruzeiro por ele erguido em 1862. Segundo Serpa (1999), este cruzeiro deu origem à capela de Santa Cruz, que gerou conflitos com a Ordem Franciscana. No entanto, suas práticas afrontaram mais as autoridades governamentais do que as eclesiásticas. De acordo com Welter (2007, p.43).

Há divergências sobre o desaparecimento deste peregrino conhecido por João Maria de Agostinho. Alguns autores dizem ter ocorrido ao redor de 1875 e outros dão datas tão díspares, como 1889, 1906, 1908 ou até 1933 no Paraguai. O que disto ressalto é que o componente de mistério sobre seu desaparecimento, raramente referido como morte, aponta para a possibilidade concreta e a esperança no seu retorno reencarnado.

Segundo Serpa (1999) e Maria Isaura Pereira de Queiroz (1957), João Maria de Jesus, o segundo profeta, era de origem francesa, seu verdadeiro nome era Anastás Marcaf. Tornou-se popular pelo fato de incorporar hábitos de João Maria Agostinho. Existem relatos sobre suas incursões no Rio Grande do Sul, em 1893, durante a Revolução Federalista. Posicionou-se a favor dos federalistas associando a república ao demônio e a monarquia a Deus. Realizava profecias, que anunciavam o fim do mundo, e tempos difíceis. Conquistou com mais intensidade o desafeto da Igreja Católica. Desapareceu por volta de 1908.

José Maria, o terceiro na cronologia, cuja historiografia apresenta registros da sua presença em Campos Novos, por volta de 1911, protagonizava profecias negativas sobre a cidade de Lages. Segundo Serpa (1999) o nome verdadeiro de José Maria era Miguel Lucena de Boaventura, ex-soldado da Força Policial do Paraná. Era alfabetizado, realizava registros da flora da região e prescrevia receitas. Houve quem reconhecesse curas praticadas por ele. Seu maior reconhecimento popular diz respeito a sua participação ou desencadeamento na Guerra do Contestado quando fugiu para Irani, local do primeiro combate e no qual foi morto. 
São João Maria, é sempre mencionado pelos caboclos como o profeta que andava pelo mundo. Deslocava-se com seus parcos objetos. "Aparecia e desaparecia”. Vivia frugalmente. Não pernoitava nas casas. Acampava-se junto às fontes de água. Fazia seu foguinho. A couve sempre esteve em seu cardápio. Rezava. Batizava as crianças, algumas das quais quase adolescentes, porque havia poucos padres no interior do Brasil e menos religiosos ainda no sertão catarinense. Benzia. Prescrevia remédios. Dava conselhos. Fazias profecias, predizendo as desgraças dos tempos futuros que eram contadas e transmitidas de geração a geração. Hoje os crentes em João Maria atualizam suas profecias, legitimando o papel do monge.

Chica Pelega é reconhecida como herdeira de João Maria no que se refere aos saberes sobre as plantas medicinais, cuidado com pessoas e animais, na simplicidade, honestidade e na luta por justiça.

Neste artigo pretendemos analisar as identidades que são construídas com base nas narrativas da população cabocla sobre o Contestado, e por outro lado, os modelos identitários elaborados para as novas gerações. Como recorte de pesquisa privilegiamos a história de Francisca Roberta, essa personagem que tem inspirado a luta e organização política das mulheres no Oeste Catarinense. A reverência à Chica Pelega também acontece por parte do Movimento das Mulheres Camponesas que, no repertório de seus hinos, entoam cânticos exaltando a bravura e coragem daquela heroína.

A identificação em torno da "guerreira do Contestado" revela novas relações e experiências de gênero, a história de Chica Pelega no imaginário social não é nova, mas sua exterioridade e publicidade por parte de mediadores políticos e religiosos têm se destacado nos últimos anos.

Calmon, cidade catarinense, que patenteou o boneco de João Maria, também confecciona bonecos de Chica Pelega, embora esta última não receba a notoriedade do primeiro, já se faz presente na iconografia representativa do Contestado. ${ }^{2}$

2 HOBAL, Michele Aparecida. Paisagens "Contestadas": o turismo como elemento transformador do espaço regional - o caso de Calmon, SC/ Brasil. Dissertação de Mestrado apresentada ao Programa de Pós-Graduação em Geografia, Setor de Ciências da Terra da Universidade Federal do Paraná. Curitiba, 2009.
A história oficial privilegiou a história de heróis, as heroínas ocupavam quando muito o posto de coadjuvantes. Em 2008, Sérgio Rubim escreve uma matéria sobre as mulheres do Contestado e alega que as mulheres tiveram pouco reconhecimento pela literatura e registros do Contestado, no entanto, "as mulheres tiveram um papel fundamental no conflito. Duas se destacaram na guerra por sua bravura: Maria Rosa, filha de Elias de Souza e Francisca Roberta, mais tarde conhecida como Chica Pelega.” 3 
Considera também que "O papel das mulheres menos conhecidas também foi fundamental. Enquanto os homens lutavam em várias frentes de combate elas cuidavam dos filhos, dos doentes e da obtenção e preparação de alimentos. Ao final da guerra foram tão humilhadas e maltratadas quanto seus maridos e filhos". ${ }^{4}$

$\mathrm{Na}$ literatura Chica Pelega é retratada por Aulo Sanford de Vasconcellos (2008), que relaciona história e ficção, segundo o autor "a Chica é muito mais fruto da minha imaginação. A não ser a parte do Exército, que tem seus registros, o Contestado foi feito por histórias orais". ${ }^{5}$

Segundo Valentini (2000) Chica Pelega "é pouco citada nos livros e para muitos nem existiu" (p.117). Independente de uma legitimidade histórica, a população cabocla e a as mulheres camponesas cultuam a história de Chica Pelega como um modelo de conduta para as mulheres. Nos últimos anos os movimentos sociais apresentam a orientação de que "é preciso fazer a história", quer dizer, agir como sujeito, "ir á luta" em busca dos direitos. A Chica Pelega torna-se referência quando o mote é a luta.

Embora as mulheres tenham sido narradas pela história como coadjuvantes, destinadas aos papéis secundários, é notório que mesmo entre as populações caboclas onde a cultura geralmente foi orientada pelo viés androcêntrico ressurja no presente a orientação de uma mulher que foge dos modelos de conduta convencionais.

Segundo Louro (1997), “observa-se que as concepções de gênero diferem não apenas entre as sociedades ou os momentos históricos, mas no interior de uma dada sociedade, ao se considerar os diversos grupos (étnicos, religiosos, de classe) que a constituem." (p. 23).

\section{História da Chica Pelega}

Conforme Valentini (2000), os pais de Chica vieram do Rio grande do Sul, lá viviam como peões em fazendas. Fixaram-se próximo à Estação de Limeira, hoje Joaçaba.

Segundo as narrativas populares a história da guerreira está estreitamente ligada aos 'feitos' de São João Maria, a menina Francisca Roberta (posteriormente chamada de Chica Pelega) seria 'querenciada' pelo monge. A mãe de "Chica" há muito tempo tentava engravidar e por motivos desconhecidos do casal, não conseguia, até que em certa feita o pai recolhera as cinzas de uma fogueira que supostamente teria sido deixada por João Maria, Vasconcellos assim descreve o fato: http://contestadoaguerradesconhecida.blogspot.com/2008/04/ as-mulheres-no-contestado.html

${ }^{4}$ Idem

5 http://www.scribd.com/ doc/18802015/CHICA-PELEGA. 
Um dia e meio de caminhada, ao norte da gleba, havia um oco de pedra onde se dizia haver descansado, por três noites seguidas, o Monge João Maria. Ali Zinho catou uns restos de carvão, seriam por certo restos da fogueira do Monge, e ao fim dessa peregrinação de três dias Chiquinha coseu-os em duas trouxinhas de pano, pendurando-as cada cônjuge no pescoço, como inseparáveis amuletos. Depois disso até as colheitas melhoraram, ambos trabalhando com maior disposição na fé, e multiplicaram-se com mais fertilidade os animais de criação. E Chiquinha, inclusive, engravidou. Engravidou sim. Por uma única vez, mas engravidou. (VASCONCELLOS, 2008, p. 43.)

Este fato torna-se importante posteriormente para entendermos a relação que foi construída em torno da Chica e do venerado Monge. Desde muito cedo a menina Francisca Roberta teria demonstrado habilidades com as ervas e o cuidado com os animais que eram acreditados e entendidos por todos como dons concedidos pelo monge à sua afilhada. A história trágica e heróica de Chica Pelega inicia como a história de tantos caboclos que foram mortos e expulsos das terras que acreditavam serem donos. Com a chegada dos jagunços nas terras da família, depois de retornarem dos trabalhos na roça, Francisca Roberta e a mãe encontraram uma cena brutal, o pai e o tio que vivia com eles estavam mortos em frente a casa e o paiol incendiados. Desesperadas e com medo, as duas foram buscar ajuda na casa da família do futuro noivo de Francisca Roberta, e a alguns quilômetros depararam-se com repetida cena brutal: todos estavam mortos, inclusive seu futuro noivo. Diante das brutais cenas e revoltadas com o massacre, as duas embrenharam-se nas matas:

Sem mais lágrimas para verter, amparando-se mutuamente, seguiram adiante apenas com a roupa do corpo, para um destino incerto. E assim perambularam por semanas e meses, nutrindo-se do que havia, já agora na companhia de tantos outros escorraçados. Francisca Roberta, por aceitação tácita, liderava essa confraria de errantes. Uma Liderança sequer pleiteada, acontecida ao natural. Ao grupo de estropiados somava-se sempre um novo membro, ali e acolá, e um desses novos aderentes falou-lhes na ressurreição do Monge o qual, naquele momento, estaria partindo de Campos Novos, para a festa do Senhor Bom Jesus de Taquaruçu, nos limites de Curitibanos. Então Francisca Roberta e o seu grupo errante para Taquaruçu rumaram os passos. (VASCONCELLOS, 2008, p.77). 
Segundo Valentini (2000) na chegada de Chica Pelega em Taquaruçu ela já assumia papel de destaque, sendo admirada por todos. Assumira logo responsabilidades no cuidado com os doentes e com as crianças. Demonstrava ter habilidades excepcionais, e com forças reunidas ao monge reencarnado José Maria, cuidavam dos doentes, crianças e idosos na comunidade Santa de Taquaruçu. Vasconcellos (2008) descreve que a dedicação de Francisca Roberta em suas tarefas era tanta que vez outra lhe rendia alguns mimos e presentes e foi assim que ganhou de um fazendeiro um cavalo e tempo depois uma espécie de mantilha de lã, felpuda como um pelego. "E vestida com seu manto/pelego e montada a cavalo, diziam que se via a Chica Pelega correndo pelos campos, e o apelido Chica Pelega ia cada vez mais se esparramando pelos barrancos de São Sebastião: Chica Pelega Guerreira de São Sebastião" (p.92). Ela transformara-se em sinônimo de força e referência a tantos escorraçados como ela. E já no primeiro ataque a comunidade Santa, a heroína surpreendeu a todos, montada em seu cavalo, empunhando a bandeira branca de cruz verde ao centro, lutando e dando coragem aos sertanejos.

A atuação de Chica Pelega é ilustrada por Vasconcelos: A Chica chega gritando "Viva a Monarquia! Viva São Sebastião!".

Eis que ali vinha Chica Pelega, a brava filha da floresta, arremetida, lançando o seu estridente e feroz grito de guerra, dos olhos jorrando-lhe chispas de raio. Em disparada, com o rosto quase colado à crina do cavalo, projetou-se por detrás das forças inimigas agrupadas e aí foi fazendo enorme estrago, golpeando de gume e de ponta com fúria desconhecida, com brutal energia provinda da fé. Surgia como um anjo da morte, como um demônio sanguinário. Eis aí Chica Pelega, mulher-centauro, a imagem viva de todas as fúrias. Batendo, atropelando, furando, nutrida por ira santa. ${ }^{6}$

Antes da sua morte, a heroína Pelega revelou sua coragem e bravura enfrentando metralhadoras armada com seu facão e a fúria orientada pela sede de justiça, além das bênçãos do Monge e de São Sebastião.

Chica Pelega, já respeitada em Taquaruçu por seu conhecimento e trato com ervas medicinais fica no reduto cuidando de doentes, velhos e crianças. Em 1914, as tropas do governo atacam novamente Taquaruçu onde ela luta bravamente. "Chica Pelega morre quando a igreja, tomada pelo fogo, desaba em cima do galpão onde se encontravam mais de 300 pessoas". $^{7}$
6 http://www.passeiweb.com/ na_ponta_lingua/livros/analises_ completas/c/chica_pelega_a_guerreira_de_taquarucu

http://contestadoaguerradesconhecida.blogspot.com/2008/04/as-mulheres-no-contestado.html 
${ }^{8}$ Telles é autor de várias letras de música sobre Chica Pelega.

${ }^{9}$ A rasga-mortalha, a exemplo da coruja, é ave noturna. Quando perturbada durante o dia, emite um sibilo rápido e agudo. Quando voa, emite um ruído forte, a exemplo de um pano rasgado, daí o nome rasga-mortalha. No escuro, o ventre e cara branca destacam-se quando iluminados.
${ }^{10}$ Acervo do CEOM - Centro de Memória do Oeste de Santa Catarina. Projeto "Inventário da cultura Imaterial Luso Brasileiro no Oeste de Santa Catarina". Entrevistadora: Mirian Carbonera.

\section{Narrativas sobre a Chica Pelega no presente.}

Vicente Telles 8 , conhecido como cancioneiro do Contestado, apresenta sua narrativa sobre a história de Chica Pelega.

Sim, por exemplo, sabe o que é a rasga-mortalha9? Coruja, já ouviu falar e o pio da coruja? Você sabe, esses dias teve uma mulher aqui e ela contava como a coruja fazia, quando ela piava, fazia a voz, eu tenho aqui a música da Chica Pelega, uma mulher que foi expulsa das estradas de ferro. O pai foi morto. No galpão e na casa colocaram fogo, recolheram as criações para os açougues e ela, quando chegou em casa, notou que o pai estava morto né, e veja bem qual seria a tua reação dentro de um quadro desse é difícil de avaliar só vivendo. Ela em vez de se deixar abater, se deprimir, ao contrário ela transformou-se em uma guerreira de São Sebastião, saiu com a mãe atravessando as matas né, porque diz que a noite ela estava lá prostrada no lado do cadáver, ela e a mãe rezando e choros lancinantes, convulsos, doloridos... Daí elas saíram e transformaramse em guerreiras de São Sebastião, então a história dessa moça é Chica Pelega, por que ela usava um pelego pra montar, pra dormir e pra aquecer os afilhados. Era madrinha de toda e qualquer criança, quem viu Chica Pelega viu chispa de raio clareando os sertões. Quer dizer dos olhos dela saiu [raio]... era uma guerreira, o olhar dela já era a guerra, quem viu Chica Pelega viu rasga-mortalha, pia nos sertão. Rasga-mortalha pia nos sertão isso é a superstição do caboclo, quando a coruja grita à noite alguma coisa de ruim vai acontecer. Quem via Chica Pelega era a mesma coisa de ouvir a rasga-mortalha, por que ela estava aí para a briga, quem viu Chica Pelega viu fogo no céu e viu sangue no chão, era guerra depois da morte dela, então começou a superstição aquela crença na volta dela. A noite clareou, os afilhados, as comadres falavam com a comadre Chica, de noite ela apareceu, a mão estendida acariciando o afilhado dela, entendeu aquela coisa de ela vai voltar, a crença de que o monge iria ressuscitar, tinha jagunço que chegava ver os cavalos de fogo de São Sebastião descendo pra sempre ajudar para o combate, outros que depois da morte de Zé Maria viram montado num cavalo branco, ele sumindo para o céu, isso já era uma coisa de exaltação mística, mas isso foi muito forte sempre existiu. ${ }^{10}$

A história de Chica Pelega é caracterizada por sucessivas perdas, o pai, o noivo e a propriedade. Seu pelego parece ter sido o que lhe restou no plano material. Revoltou-se com as injustiças e torna-se a guerreira de São Sebastião. A vida só tinha sentido se fosse para lutar contra todas as injustiças sofridas e pelos seus. Segundo Vasconcellos: 
Chica Pelega representa mais que tudo, um emblema de luta, e nesse recado se alicerça a sua maior importância. $\mathrm{O}$ sonho da implantação de um Império Caboclo na região do Contestado assenta-se principalmente no grito em favor do direito à terra, encontrando no messianismo desesperado agasalho. Chica Pelega, independentemente da sua existência física, significa a indignada síntese de uma coletividade injustiçada. Porque Chica Pelega é algo no Plural.

(Vasconcellos, 2008, p.21)

Segundo as narrativas da população cabocla, Chica convidava homens e mulheres para a luta, sua coragem era expressa no modo de organizar o grupo para a guerra, conforme a letra da música:

Quem viu CHICA PELEGA/ viu Chispa de raio clareando no sertão,

Crente na fala do monge,/ CHICA PELEGA bradou, monte comadre,

Traga o afilhado que o tempo de briga é chegado.

/: QUE O TEMPO DE BRIGA É CHEGADO

NA CIDADE SANTA DE TAQUARUÇU:/

Quem viu CHICA PELEGA, / viu fogo no céu e sangue no chão, Crente na fala do monge, /CHICA PELEGA bradou, monte comadre,

Traga o facão, que é pra defender nosso chão.

/: QUE É PRA DEFENDER NOSSO CHÃO

NA CIDADE SANTA DE TAQUARUÇU

Quem viu CHICA PELEGA,/ viu rasga mortalha piar no sertão, Crente na fala do monge, /CHICA PELEGA gemeu, monte comadre

Que importa a morte se o amor que vier for mais forte.

:/SE O AMOR QUE VIER FOR MAIS FORTE

NA CIDADE SANTA DE TAQUARUÇU:/

Lá vem CHICA PELEGA, vem feito visage ao luar do sertão,

Vem a cavalo no tempo, na voz do vento a bradar,/ monte comadre

São Sebastião vem vindo salvar o sertão.

:/VEM VINDO SALVAR O SERTÃO

NA CIDADE SANTA DE TAQUARUÇU:/11

As músicas de luta transformaram-se na principal forma de divulgação da história da guerreira, no Oeste Catarinense são divulgadas através de obras de cunho religioso como "O
${ }^{11}$ DIOCESE DE CHAPECÓ. O povo canta sua vida. Secretariado Diocesano de Pastoral. Passo Fundo: Edição Berthier, 1986. 
${ }^{12}$ Entrevista realizada por Josiane Geroldi. povo canta sua Vida" distribuída pelo Secretariado Diocesano de Pastoral. Em cidades como Chapecó, a menção à Chica Pelega está diretamente relacionada aos cânticos que são entoados durante Romarias e caminhadas pela Terra comuns nas comunidades caboclas do interior. Assim como São João Maria, Chica Pelega é transformada através das narrativas populares em um ícone que representa um modelo de conduta e luta de grupos subalternos.

Em Chapecó, na Linha Almeida, o Padre Zé, reconhecido por valorizar e incentivar a cultura cabocla fala sobre o livro da Diocese que apresenta músicas da Chica Pelega.

É, esse Livro, nós usávamos mais em dia de celebração, assim de tipo caminhada, romaria. Romaria da terra, né, eles usavam muito. Porque ali nessa história do Contestado essa Chica Pelega, foi ela quem liderou [...] Fizeram essa música, mas é aqui nessa região do Contestado, né teve uma Romaria em, como é que é, Taquaruçu, acho que é. É a música fala no Taquaruçu!

Tinha uns guri, aqui, que cantavam, é claro, a gente não usa esse canto na liturgia, sabe né, é só um canto de Luta, de movimento. Os movimentos sociais usam muito, os sem terra usam muito. ${ }^{12}$

Conforme Renk e Savoldi (2009), a presença de "São João Maria” é recorrente nas narrativas das populações caboclas no Oeste Catarinense. A presença não remete apenas ao passado, muitos entrevistados alegam vê-lo no presente. $\mathrm{O}$ imaginário não se refere apenas a uma história que foi alimentando a memória do grupo, a história do "São João Maria" continua sendo atualizada em consonância com as experiências vividas. As aparições e interlocuções no cotidiano são narradas de modo a legitimar a existência do mesmo. Concebemos imaginário social com base na concepção de Baczko (1985) como uma produção coletiva sobre as relações imagéticas de distintos grupos. Nesse sentido “o imaginário social é cada vez menos considerado como uma espécie de ornamento de uma vida material considerada como a única 'real'." (BACZKO, 1985, p.297).

De acordo com a Narrativa de Vicente Telles há a crença de que Chica Pelega possa aparecer quando o contexto for conflituoso, como herdeira de João Maria, também lhe atribuem a possibilidade de volta para auxiliar nos conflitos do cotidiano. A coruja é o sinal da aparição, ou melhor, o grito da coruja.

Apresentamos a trajetória de Francisca Roberta, Chica Pelega de Limeira a Taquaruçu. À medida que avança em direção aos 
redutos aumenta a sua canonização popular, a exemplo do tratado por Oscar Saéz (1996). Neste texto, seja ou não ficcionalizada a vida da heroína, o que nos interessa foi a reconversão de "jagunça" por alguns segmentos envolvidos no Contestado e transformada, emblematicamente, como no rol das mulheres destemidas e que assumem a luta.

Entre a certeza e incerteza da realidade da existência física, em seu torno giram romances, a indústria fonográfica e ações do clero católico progressista. Chica Pelega torna-se presente nas vozes que entoam e nos ensinamentos diários, nas histórias ouvidas e naquelas contadas. Outro aspecto é o papel desempenhado pelas mulheres por ocasião do Contestado. Tratavase sociedade androcêntrica com reduzido espaço às mulheres. Recuperar a história é uma forma de muitas mulheres lutarem pelo empoderamento e constituírem-se em sujeitos da história.

\section{Referências}

AURAS, Marli. Guerra do Contestado: a organização da irmandade cabocla. Florianópolis: Ed. da UFSC, 1984.

BACZKO, Bronislaw. A imaginação social. Einaudi, N. 5 Antropos, 1985.

CALAVIA SÁEZ, Oscar. Fantasmas falados: mito, escatologia e história no Brasil. Campinas: Editora da UNICAMP, 1996.

DIOCESE DE CHAPECÓ. O povo canta sua vida. Secretariado Diocesano de Pastoral. Passo Fundo, Edição Berthier, 1986.

FELIPPE, Euclides José. O último Jagunço. Curitibanos: Universidade do Contestado, 1995.

HOBAL, Michele Aparecida. Paisagens “Contestadas”: o turismo como elemento transformador do espaço regional - o caso de Calmon, SC/ Brasil. Dissertação de Mestrado apresentada ao Programa de Pós-Graduação em Geografia, Setor de Ciências da Terra da Universidade Federal do Paraná. Curitiba, 2009.

LOURO, Guacira Lopes. Gênero, sexualidade e educação. Uma perspectiva pós-estruturalista. Petrópolis, RJ: Vozes, 1997.

QUEIROZ, Maria Isaura Pereira. La Guerre Sainte au Brésil; Le Mouvement Messianique du Contestado. São Paulo: USP, 1957. 
RENK, A; SAVOLDI, A. Contestado: tropos, roteiros, imagens e linguagens. Cadernos do CEOM (UNOCHAPECO), Chapecó, v. n. 20, n. ano 17, 2004.

RENK, Arlene e SAVOLDI, Adiles. Os caminhos de São João Maria: manifestações populares da fé no Monge. In: http://www.ram2009. unsam.edu.ar/GT/GT\%2049\%20\%E2\%80\%93\%20Turismo,\%20Cultura\%20y\%20Sociedad/GT49\%20-\%20Ponencia\%20\%5BSavoldi-\%20 Renk\%5D.pdf

SERPA. Élio. A Guerra do Contestado (1912-1916). Florianópolis: Editora da UFSC, 1999.

THOMÉ, Nilson. Trem de Ferro: história da ferrovia no Contestado. 2. ed. Florianópolis: Lunardelli, 1983.

. Breve História da Guerra do Contestado. Caçador: UnC Campus Caçador; Museu do Contestado; INCON, 2005.

VALENTINI, Delmir José. Da cidade santa à corte celeste: memórias de sertanejos e a guerra do contestado. 2. ed. Caçador: UnC, 2000.

VASCONCELLOS, A.Sanford de. Chica Pelega - A Guerreira de Taquaruçu. Florianópolis: Insular, 2.ed.2008.

VINHAS DE QUEIROZ, Maurício. Messianismo e conflito social; a guerra sertaneja do Contestado (1912-1916). Rio de Janeiro: Civilização Brasileira, 1966.

WELTER, Tânia. O profeta São João Maria continua encantando no meio do povo. Um estudo sobre os discursos contemporâneos a respeito de João Maria em Santa Catarina. Tese apresentada ao Programa de Pós-Graduação em Antropologia Social da UFSC, 2007. 


\section{Abstract}

The text discusses popular narratives of the Caboclo people of Western Santa Catarina. It selects the character known as Chica Pelega, who had accompanied the facts of the "Contestado" war, moving from Limeira (the present-day Joaçaba) towards the North, to the location of the fighting. It retrieves, critically, the context in which the character would have appeared. It analyzes the revival of and the uses made by the local population of Chica Pelega.

Key words: The "Contestado" war; narratives; Chica Pelega. 
